\title{
The Effect of the Commonly Used Antidepressant Drug Amitriptyline (TCAs) on the Salivary Glands
}

\author{
Gamal Eldin Z. Elsharkawy ${ }^{1,2}$ and Turki Y. Alhazzazi ${ }^{3 *}$ \\ ${ }^{1}$ Department of Diagnostic Oral Sciences, Faculty of Dentistry, King Abdulaziz University, Jeddah, Saudi Arabia \\ ${ }^{2}$ Cairo University, Faculty of Oral \& Dental Medicine, Cairo, Egypt \\ ${ }^{3 *}$ Department of Oral Biology, Faculty of Dentistry King Abdulaziz University, Jeddah, Saudi Arabia
}

Received: September 22, 2016; Accepted: October 03, 2016; Published: October 06, 2016

*Corresponding author: Turki Y. Alhazzazi, BDS, FRCD(C), PhD, Chairman, Department of Oral Biology, Faculty of Dentistry, King Abdulaziz University, Jeddah, Saudi Arabia; Tel No: 009662-640-3443 ext 22024; E-mail: talhazzazi@kau.edu.sa

\begin{abstract}
Background: Our goal was to evaluate whether amitriptyline harms the salivary glands; we used the S-100 protein as a marker for cell injury. This could partially explain the xerostomia side-effect during amitriptyline treatment.

Methods: A total of 35 male albino rats were used in this study and divided into 3 groups. Group I was the control $(n=5)$. Group II $(n=15)$ rats were treated once daily with a single oral dose of amitriptyline $(5 \mathrm{mg} / \mathrm{kg})$ for 8 weeks. Group III $(n=15)$ rats were treated twice daily with amitriptyline $(10 \mathrm{mg} / \mathrm{kg})$ for 8 weeks. All rats were sacrificed and the submandibular glands were dissected and stained with $\mathrm{H} \& \mathrm{E}$ and probed for S-100 protein using immunohistochemistry. A blinded pathologist graded the staining intensities as low, moderate or high.

Results: Our data showed that amitriptyline causes dosedependent degenerative changes in submandibular salivary glands when used once $(5 \mathrm{mg} / \mathrm{kg})$ or twice $(10 \mathrm{mg} / \mathrm{kg})$ versus untreated controls. These changes were also associated with a dose-dependent increase in the S-100 protein expression levels.
\end{abstract}

Conclusions: Our study demonstrated that frequent use of amitriptyline is associated with degenerative changes in salivary glands. This may partially explain xerostomia as a side-effect. More studies are needed to unlock other causes of this side-effect.

Keywords: Amitriptyline; Salivary Gland; Submandibular Glands; Antidepressant; S-100 protein

\section{Introduction}

Depression is a mental illness in which people often have feelings of hopelessness and worthlessness suicidal thoughts. This disease can affect any person regardless of age, gender, race, or socioeconomic status. Thus, the use of antidepressants, unfortunately, has become very common [1]. However, like other drugs, antidepressants have several side-effects. One of the major complaints of patients undergoing this class of medications is dry mouth (xerostomia) [2]. Although, several studies have shown that antidepressants induce a decrease in salivary flow, the cause of this side-effect is still poorly understood [2,3]. In an attempt to control the adverse effects of these drugs, clinicians can reduce the dose, but this also reduces the efficacy of treatment [4]. Thus, many studies have concluded that to achieve proper therapeutic dosage, clinicians must individualize their treatment for each patient $[5,6]$.

Amitriptyline is a well-recognized and widely used Tricyclic Antidepressant (TCAs) that is approved mainly for the treatment of depression. It has at least equal efficacy against depression as the newer generation of antidepressants such as Specific Serotonin-Reuptake Inhibitors (SSRI), but it also has more sideeffects [7] including dizziness, insomnia, fatigue, constipation, and xerostomia [8]. As a result, attempts have been directed toward elucidating the cause of the side-effects to diminish their potential hazards [9].

The S-100 protein has been used as a marker for cell injury in the nervous system $[10,11]$. Thus, the aim of our study was to investigate whether amitriptyline does indeed cause harmful cell injury to the salivary glands in vivo utilizing S-100 protein as a marker. This may explain, at least in part, the patients complaint of xerostomia.

\section{Materials and Methods}

Animals: This study used 35 healthy adult albino rats weighing 180-200 g. The rats were housed individually in stainless steel cages and were fed on a standardized laboratory balanced diet and water (ad libitum). The rats were divided into 3 groups:

- Group I (Control Group; $\mathrm{n}=5$ ): Untreated group; rats were given only water.

- Group II ( $\mathrm{n}=15)$ : Rats received a daily single oral dose of amitriptyline equivalent to the therapeutic dose of (5 $\mathrm{mg} / \mathrm{kg}$ ) using an oro-pharangeal metallic curved tube for 8 weeks. 
- Group III (n=15): Rats received a daily dose of amitriptyline equivalent to double the therapeutic dose of $(10 \mathrm{mg} / \mathrm{kg})$ using the same route of administration for 8 weeks.

At the end of the experimental period, all rats were scarified and the submandibular glands were dissected and stained with Hematoxylin and Eosin (H\&E). In addition, a total of 115 samples (control), 345 samples (Group II), and 345 samples (Group III) were examined and probed for the S-100 protein (monoclonal mouse primary antibody) using immunohistochemistry staining approach as described elsewhere [12]. Staining intensities were graded in a blinded manner as low, moderate or high.

\section{Statistical Analysis}

For immunohistochemistry samples, the McNemar test was used to compare between groups. The difference was considered significantly different when ${ }^{*} \mathrm{p} \leq 0.05$ or ${ }^{* *} \mathrm{p} \leq 0.01$.

\section{Results}

\section{Amitriptyline Causes Degenerative Changes in Salivary Glands}

- Group I (Control group): The submandibular salivary glands looked normal and were composed of serous acini, few mucous acini, various types of ducts and Connective Tissue (C.T) stroma. The serous acini were round, small, and with a narrow lumen. They were lined with a single layer of pyramidal cells with basophilic cytoplasm. Their nuclei were large, prominent, spherical, and were basally situated. Striated ducts were also seen in between the secretory and centrally placed nuclei with an intensely eosinophilic cytoplasm. They were characterized by their basal striations. These ducts were clearly recognized in the H\&E sections. The granular convoluted tubules were the most characteristic structure in the rat submandibular salivary glands. They were lined by columnar cells with dark and centrally placed nuclei. They were packed with eosinophilic granules. The excretory ducts were found between the lobules of the glands surrounded by C.T. stroma and lined by pseudostratified columnar epithelium with goblet cells (Figure 1A \& B).

- Group II: Histological examination of the submandibular salivary glands treated with a daily single dose of amitriptyline $(5 \mathrm{mg} / \mathrm{kg})$ for 8 weeks showed mild to moderate atrophic changes. Serous acini and striated ducts showed a moderate degree of intercellular vacuolization. The nuclei were flattened and pushed against the basal lamina membrane of the cells. There was also a complete loss of nuclei in some cells. Some of the granular convoluted tubules showed a decreased amount of esinophilic granules with vacuolization. There was slight extravasation of red blood cells in between the secretory portions and the ducts. The excretory ducts had a thick epithelial lining and a circumscribed wide lumen containing stagnant secretory material. Dilated blood vessels engorged with red blood cells were also detected (Figure 1C \& D)

- Group III: Histological examination of the rat submandibular salivary glands treated twice daily with amitriptyline $(10 \mathrm{mg} / \mathrm{kg}$ ) for 8 weeks showed severe to atrophic changes. The secretory portions revealed severe shrinkage and some had complete degeneration. Severe widening of the connective tissue septa was observed. The serous secretory portions lost their typical form and became irregularly shaped. The excretory ducts were dilated with limited secretion. There were irregular and degenerated granular convoluted tubules. Some specimens showed vacuolization of serous acini and accumulation of eosinophilic materials in their lumens. Degenerated granular convoluted tubules with pyknotic basal flattened nuclei were also observed_(Figure 1E \& F).

Histological cellular localization pattern of S-100 protein in amitriptyline-treated groups versus controls

Group I (control group): There was very low

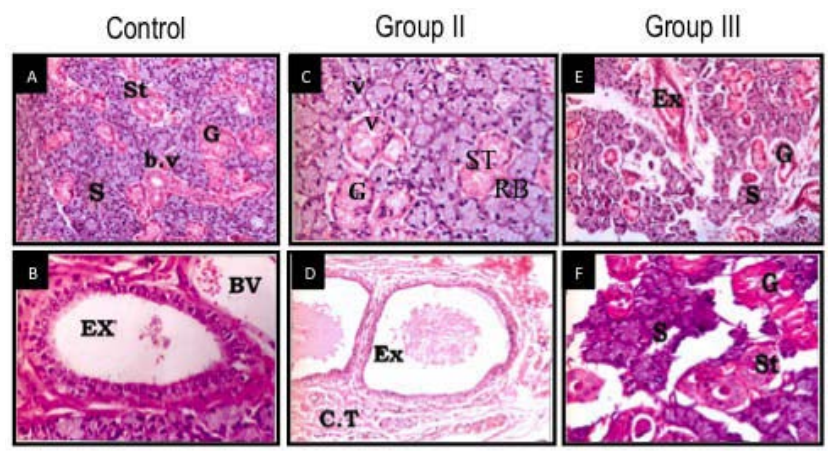

Figure 1: Amitriptyline causes degenerative changes in salivary glands

(A) Representative micrograph (H\&E staining, magnification x200) of rat submandibular salivary gland of the control group (group I) showing normal appearance of serous acini (S), striated ducts (St), granular convoluted tubules $(G)$ and blood vessels $(b, v)$. (B) The excretory duct (EX) is lined with pseudostratified columnar epithelium and surrounding connective tissue stroma with blood vessels (BV) collagen fibres and fibroblasts (H\&E staining, magnification $\mathrm{x} 400$ ). (C) Representative micrograph (H\&E staining, magnification x200) of rat submandibular gland from group II showing vacuolization (V) of the secretory portions and granular convoluted tubules (G), loss of nuclei of striated duct (St) and extravasated red blood cells in between the secretory portions and ducts (RB). (D) The dilated excretory duct (EX) has stagnated secretion and severe fibrosis of the connective tissue stroma (C.T) (H\&E staining, magnification x200). (E) Representative micrograph (H\&E staining, magnification x200) of rat submandibular glands from group III showing vacuolization and shredding of serous acini (S), dilatation of the excretory duct with stagnant secretion (EX), and irregular degenerated granular convoluted tubules with decreased eosinophlic granules (H\&E staining, magnification x200). Panel (F) shows disorientation of serous acini (S), shredded granular convoluted tubules (G), and complete loss of some secretory portions leaving large spaces and striated ducts with eosinophilic material in its lumen (St) (H\&E staining, magnification $\mathrm{x} 400$ ). 
immunohistochemical staining of the S-100 protein in the secretory portions and myoepithelial cells of the salivary glands. There was low staining of S-100 in the striated ducts and granular convoluted tubules (Figure 2A a).

Group II: Moderate staining intensity of S-100 protein was observed in the submandibular glands of this group versus controls. This staining was associated with the secretory portions, striated ducts, excretory ducts, and granular convoluted tubules. In addition, moderate staining was also found in and around the blood vessels and connective tissue stroma (Figure 2A b).

Group III: There was also moderate to high intensity staining of the S-100 protein in the secretory portions of the submandibular gland versus other groups. This included the striated excretory ducts and granular convoluted tubules. The connective tissue stroma and blood vessels had high staining for the S-100 protein (Figure 2A c).

The S-100 protein possesses a dose dependent increase of expression upon higher doses of amitriptyline treatment

In submandibular salivary glands, the S-100 protein is intrinsically expressed in low levels in $77 \%$ of the control samples. The remaining $23 \%$ showed only moderate expression levels (Figure 2B). Upon a daily single dose of amitriptyline treatment ( $5 \mathrm{mg} / \mathrm{kg}$ ) for 8 weeks (Group II), $88.4 \%$ of the treated samples had moderate S-100 protein expression; $6.1 \%$ were low and $5.5 \%$ were high (Figure $2 \mathrm{~B} ;{ }^{*} \mathrm{p} \leq 0.05$ ). In contrast, when we doubled the dose (10 mg/kg twice per day; Group III), $81 \%$ of the samples have high S-100 protein expression levels versus $5 \%$ and $14 \%$ for the low and high expression levels, respectively (Figure 2B; ${ }^{*} \mathrm{p} \leq 0.5$ ). Staining intensities between the groups were also statistically significant (Figure $2 \mathrm{~B}{ }^{* *} \mathrm{p} \leq 0.01$ ). Table 1 summarizes S-100 protein expression levels. The S-100 protein has a dose-dependent increase in expression at higher doses of amitriptyline.

\section{Discussion}

Saliva is a unique, complex and versatile fluid that serves many purposes in the oral and pharyngeal environment. It is a lubricant that facilitates swallowing, acts as a mechanical device to clean the teeth, is an immunological barrier, and works as taste stimulator [13,14]. Diminished salivary output from the major and minor salivary glands is called "Salivary Hypofunction" and the subjective complaint of a dry mouth is termed xerostomia [15]. This leads to numerous consequences including dental caries, candidiasis, erosion and ulceration of mucosal tissues as well as dysgeusia, dysphagia, gingivitis, and alteration of taste $[13,16]$.

Antidepressants such as amitriptyline cause xerostomia and therefore affect the general oral health of the medicated patient $[17,18]$. It is important to understand the mechanism of this adverse side-effect to overcome this major disadvantage and improve future antidepressants.

The histological examination obtained here shows that amitriptyline adversely affects rat submandibular salivary glands. The effect is dose-dependent. The submandibular salivary glands suffered from severe atrophy and shrinkage with some areas showing complete acinar loss. There was also severe

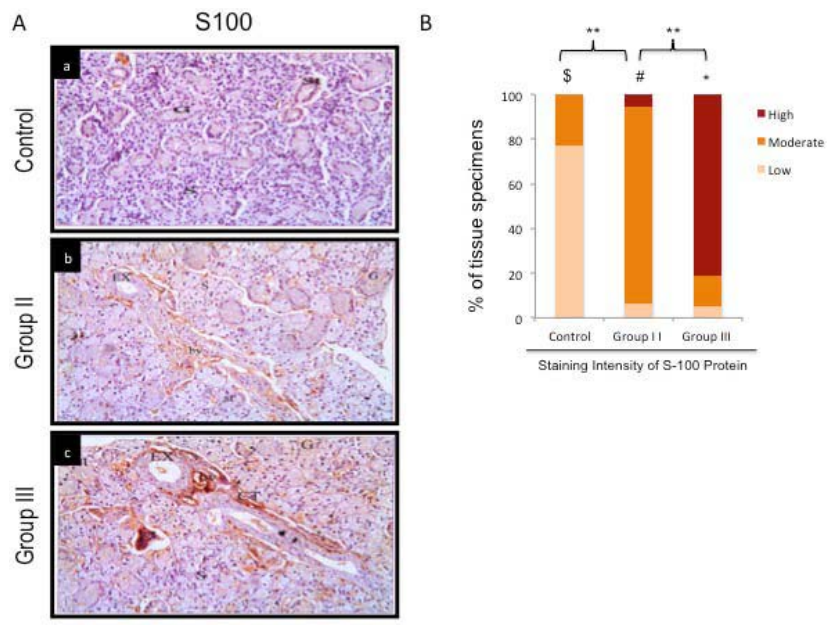

Figure 2: Histological cellular localization pattern of S-100 protein in amitriptyline-treated groups versus controls (Aa) Representative micrograph of rat submandibular gland of group I (control) showing weak staining of the S-100 protein in the myoepithelium cell and secretory portions (S). There was also mild staining in the granular convoluted tubules (G) and striated duct (St). (Ab) Representative micrograph of rat submandibular gland of group II showing moderate staining of S-100 protein in the secretory portions $(\mathrm{S})$, duct system striated duct (St), excretory duct (EX), granular convoluted tubules (G), and blood vessels (bv). (Ac) Representative micrograph of rat submandibular gland of group II showing severe staining of S-100 protein in the secretory portions (S), duct system, striated duct (St), excretory duct (EX), granular convoluted tubules (G), connective tissue stroma (CT), and blood vessels (bv). (Magnification, x200). (B) Bar chart illustrating the percentage of submandibular tissue samples staining intensities for S-100 protein as data presented in Table 1. Staining intensities were graded as low, moderate or high by a blinded pathologist. Significant difference, ${ }^{\$} P \leq .05$; low vs moderate in the control group. ${ }^{\#} \leq \leq .05$; moderate vs low or high staining in group II; ${ }^{*} P \leq .0 .05$; high vs moderate or low in group III. ${ }^{*} P \leq .0 .0$; control vs group II/III (low staining); group II vs control/group III (moderate staining); and group III vs group III (high staining).

Table 1: The S-100 protein expression levels in the amitriptyline treatment groups vs. control.

\begin{tabular}{|l|l|l|l|l|}
\hline & $\begin{array}{l}\text { Low } \\
\text { Intensity } \\
\text { (\%) }\end{array}$ & $\begin{array}{l}\text { Moderate } \\
\text { Intensity } \\
\text { (\%) }\end{array}$ & $\begin{array}{l}\text { High } \\
\text { Intensity } \\
\text { (\%) }\end{array}$ & $\begin{array}{l}\text { Total No. } \\
\text { of Tissue } \\
\text { Samples }\end{array}$ \\
\hline $\begin{array}{l}\text { Control } \\
\text { (Untreated) }\end{array}$ & $\$ 88(77)$ & $27(23)$ & $0(0)$ & 115 \\
\hline $\begin{array}{l}\text { Group II } \\
\text { (5 mg/kg) }\end{array}$ & $21(6.1)$ & $\# 305(88.4)$ & $19(5.5)$ & 345 \\
\hline $\begin{array}{l}\text { Group III } \\
\text { (10 } \mathbf{~ m g / k g ) ~}\end{array}$ & $17(5)$ & $49(14)$ & $* 279(81)$ & 345 \\
\hline Sign & & & & \\
\hline
\end{tabular}

Significant Difference: ${ }^{\$} P \leq 0.05$; low vs moderate in the control group. ${ }^{\#} P \leq 0.05$; moderate vs. low or high staining in group II, ${ }^{*} P \leq .0 .05$; high vs moderate or low in group III. 
acinar vacuolization and degeneration of the granular convoluted tubules.

The intracytoplasmic vacuolization that appeared within the secretory portions might be due to intracytoplasmic degeneration of a mostly fatty nature. However, in routinely processed H\&E sections, most of the lipid droplets dissolve during fixation and processing leaving only empty vacuoles. In this study, stagnation of secretion in the ducts might be due to impaired flow rates. This is reflected in glandular dysfunction and resulting xerostomia. Studies have reported that one mechanism by which tricyclic antidepressants exerted xerogenic effects was via a significant decrease in sodium and increase in potassium ion exchange [2]. Others have shown that these drugs possess xerogenic effects by inhibiting the salivary reflex in the central nervous system that regardless of antidepressant class [19]. In our study, we believe that impaired salivary flow is caused, at least in part, by direct cell injury as seen in the dose-dependent increase in the cell injury marker S-100.

The S-100 protein is upregulated in diseased tissue with background expression in the nervous system, chondrocytes, fat cells, lymphoid tissue, brain, and salivary glands [20,21,22,23]. Our study showed that antibodies against S-100 protein are a useful marker for cellular injury to salivary glands after the treatment with different doses of amitriptyline. This injury is dose-dependent as shown by the increase in the S-100 protein expression levels with increased amitriptyline drug treatment.

\section{Conclusion}

Our data demonstrates that the frequent use of amitriptyline is associated with degenerative changes in the salivary glands of a rat model. The reversibility of these changes has yet to be determined. Clinicians prescribing antidepressant drugs such as amitriptyline should used caution and be aware of oral sideeffects when using more frequent or higher doses to treat their patients. More studies are needed to understand the causes of these side-effects and to develop more safe and effective antidepressants.

\section{Acknowledgments}

The authors thank Kalvin Balucanag and his team for helping us with data analysis. We also would also like to thank the support received from Deanship of Scientific Research (DSR), King Abdulaziz University, Jeddah, Saudi Arabia.

\section{Financial Support}

None declared.

\section{Conflict of Interest}

There are no conflicts of interest.

\section{Ethical Approval}

The experimental procedures were approved by the institution of animal care and ethical committee of the Faculty of Oral \& Dental Medicine, Cairo University (Code 711212), and performed in full accordance with the World Medical Association Declaration of Helsinki.

\section{Author's Contributions}

GE and TYA participated in the literature review search and the manuscript preparation. GE participated in the overall study design, data collection and analysis. TYA also helped with the data tabulation, figures preparation, and statistical analysis. TYA revised and critically reviewed the final version of the manuscript. Both authors agreed on the final version of the manuscript.

\section{References}

1. Ciuna A, Andretta M, Corbari L, Levi D, Mirandola M, Sorio A, et al Are we going to increase the use of antidepressants up to that of benzodiazepines? Eur J Clin Pharmacol. 2004;60(9):629-634.

2. Hunter KD, Wilson WS. The effects of antidepressant drugs on salivary flow and content of sodium and potassium ions in human parotid saliva. Arch Oral Biol. 1995;40(11):983-989.

3. Kopittke L, Gomez R, Barros HM. Opposite effects of antidepressants on unstimulated and stimulated salivary flow. Arch Oral Biol. 2005;50(1):17-21.

4. Bollini P, Pampallona S, Tibaldi G, Kupelnick B, Munizza C. Effectiveness of antidepressants. Meta-analysis of dose-effect relationships in randomised clinical trials. Br J Psychiatry. 1999;174:297-303.

5. Filakovic P, Petek A. Personalized pharmacotherapy in psychiatry Psychiatr Danub. 2009;21(3):341-346.

6. de Leon J. The future (or lack of future) of personalized prescription in psychiatry. Pharmacol Res. 2009;59(2):81-89.

7. Barbui C, Hotopf M. Amitriptyline v. the rest: still the leading antidepressant after 40 years of randomised controlled trials. $\mathrm{Br}$ J Psychiatry. 2001;178:129-144.

8. Bockner S. Side-Effect of Amitriptyline. Br Med J. 1965;1(5443):1188.

9. Haller I, Lirk P, Keller C, Wang GK, Gerner P, Klimaschewski L. Differential neurotoxicity of tricyclic antidepressants and novel derivatives in vitro in a dorsal root ganglion cell culture model. Eur J Anaesthesiol. 2007;24(8):702-708.

10. Michetti F, Massaro A, Russo G, Rigon G. The S-100 antigen in cerebrospinal fluid as a possible index of cell injury in the nervous system. J neurol sci. 1980;44(2-3):259-263.

11. Korfias S, Stranjalis G, Papadimitriou A, Psachoulia C, Daskalakis G, Antsaklis A, et al. Serum S-100B protein as a biochemical marker of brain injury: a review of current concepts. Curr med chem. 2006;13(30):3719-3731.

12. Johnsone A, Thorpe R. Immunochemistry in Practice. 3rd edition. Blackwell Science ltd. University Press Cambridge. 1996; Chapter 2:34-40

13. Benn AM, Thomson WM. Saliva: an overview. N Z dent J. 2014;110(3):92-96

14. Llena-Puy C. The role of saliva in maintaining oral health and as an aid to diagnosis. Med Oral Patol Oral Cir Bucal. 2006;11(5):E449-455.

15. Atkinson JC, Grisius M, Massey W. Salivary hypofunction and xerostomia: diagnosis and treatment. Dent Clin North Am. 2005;49(2):309-326

16. Saleh J, Figueiredo MA, Cherubini K, Salum FG. Salivary hypofunction: an update on aetiology, diagnosis and therapeutics. Arch Oral Biol. 2015;60(2):242-255. 
17. Rundegren J, van Dijken J, Mornstad H, von Knorring L. Oral conditions in patients receiving long-term treatment with cyclic antidepressant drugs. Swed dent J. 1985;9(2):55-64.

18. Daly C. Oral and dental effects of antidepressants. Aust prescr. 2016;39(3):84.

19. Johnsson M, Winder M, Zawia H, Lodoen I, Tobin G, Gotrick B. In vivo studies of effects of antidepressants on parotid salivary secretion in the rat. Arch Oral Biol. 2016;67:54-60.

20. Takahashi K, Yamaguchi $\mathrm{H}$, Ishizeki J, Nakajima T, Nakazato Y Immunohistochemical and immunoelectron microscopic localization of S-100 protein in the interdigitating reticulum cells of the human lymph node. Virchows Arch B Cell Pathol Incl Mol Pathol. 1981;37(2):125-135.

21. Nakajima T, Watanabe S, Sato Y, Kameya T, Hirota T, Shimosato Y. An immunoperoxidase study of S-100 protein distribution in normal and neoplastic tissues. Am J surg pathol. 1982;6(8):715-727.

22. Kumar H, Lakhotia M, Pahadiya H, Singh J. To study the correlation of serum S-100 protein level with the severity of stroke and its prognostic implication. J neurosci rural pract. 2015;6(3):326-330.

23. Lombardi T, Samson J. S-100 protein in normal and pathologic oral tissues. A review. Swiss Dent J. 1993;103(4):413-418. 